\title{
Racismo, neorracismo y educación ${ }^{1}$
}

\author{
Racism, neo racism and education
}

Juan Illicachi Guzñay²
andres1_517@hotmail.com

\section{Resumen}

El trabajo analiza los discursos y las prácticas de discriminación racial individuales e institucionales operantes en el sistema escolar e incluso su ejercicio en las mallas más finas y reticulares, y cómo los sujetos racializados al tomar conciencia étnica y social se están dando alternativas distintas al sometimiento: negociando, resinificando, disputando dentro de la misma estructura. Pero antes, exploro los dispositivos contra la discriminación racial en el marco legal de corte internacional y nacional y su operación en términos de ambigüedad y contradicción, y cómo la emergencia del neoracismo en base a la llamada "posciencia" (ingeniería genética) instaura la posibilidad de una nueva y más grave forma de segregación racial, basada en el genotipo o en el conjunto de información genética de cada sujeto.

\section{Palabras claves}

Educación, legalidad, racismo, neorracismo, posciencia, resistencia, vestimenta indígena.

\begin{abstract}
This work analyzes the discourses and the individual and institutional practices of racial discrimination that operate in the school system and even its exercise in the thinner and more reticulate nettings, and how the racialized subjects are giving themselves alternatives to submission by raising their ethnic and social awareness by: negotiating, resinifying, challenging the system from within. Before that, I explore the devices against racial discrimination in international and national courts' legal frameworks and their operation in terms of ambiguity and contradiction, and how the emergence of neo racism based on the so-called "post science" (genetic engineering) establishes the possibility of a new and more serious form of racial segregation, based on the genotype or the set of genetic information available from each subject.
\end{abstract}

Keywords

Education, legality, racism, neo racism, post science, resistance, indigenous clothing.

Forma sugerida de citar:

Illicachi Guzñay, J. (2015). Racismo, neorracismo y educación. Universitas, XIII (22), pp. 95-115. Quito: Editorial Abya-Yala/Universidad Politécnica Salesiana.

1 El presente artículo es parte de un proyecto más amplio de investigación: "La interculturalidad en el modelo educativo de la educación general básica en el cantón Riobamba", que viene impulsando la Universidad Nacional de Chimborazo-Facultad de Ciencias de la Educación.

2 Doctor en Antropología Social, Centro de Investigaciones y Estudios Superiores en Antropología Social (CIESAS, D.F). Profesor-investigador de la Universidad Nacional de Chimborazo. Líneas de investigación: poder, religión e interculturalidad. 


\section{Marco legal}

En el contexto internacional, el 21 de diciembre de 1965, la Asamblea General de las Naciones Unidas aprobó la Convención Internacional sobre la Eliminación de Todas las Formas de Discriminación Racial. Una vez que este instrumento fue ratificado por 27 Estados firmantes (entre ellos Ecuador), entró en vigencia el 4 de enero de 1969 (Valencia, s/f). Una de las declaratorias de las Naciones Unidas sobre la eliminación de todas las formas de discriminación racial en su Art. 2 numeral 2 menciona: "ningún Estado fomentará, propugnará o apoyará, con medidas policiacas o de cualquier otra manera, ninguna discriminación fundada en la raza, el color o el origen étnico, practicada por cualquier grupo, institución o individuo"; concomitante a esta declaratoria, en el Art.10 la ONU menciona:

Las Naciones Unidas, los organismos especializados, los Estados y las organizaciones no gubernamentales tienen el deber de hacer cuanto les sea posible para fomentar una acción enérgica que, combinando las medidas jurídicas y otras medidas de índole práctica, permita la abolición de todas las formas de discriminación racial. En particular, deben estudiar las causas de dicha discriminación a fin de recomendar medidas adecuadas y eficaces para combatirla y eliminarla.

En esta línea de dispositivos contra la discriminación, la constitución de la OIT se inscribe en el periodo subsiguiente a la primera Guerra Mundial, una comisión de trabajo establecida en la Conferencia de Paz de París. En ella se reconoce: "Los pueblos indígenas y tribales deberán gozar plenamente de los derechos humanos y libertades fundamentales, sin obstáculos ni discriminación. Las disposiciones de este Convenio se aplicarán sin discriminación a los hombres y mujeres de esos pueblos"3. Es más, en el Ecuador, a partir del 15 de noviembre de 1998, está vigente el Convenio No. 169 de la OIT (Organización Internacional del Trabajo), el cual obliga al gobierno ecuatoriano a presentar una memoria anual a este organismo internacional para verificar si el convenio se está cumpliendo (García, 2007) De la misma manera en 1969, Ecuador, también se adhiere a la Convención Internacional sobre la Eliminación de Todas las Formas de Discriminación Racial, presentado la candidatura para ser miembro

3 Ver en Art. 3, numeral I del Convenio No. 169 de la OIT. 
del naciente Comité a Luis Valencia Rodríguez, aunque en el 2008 la Cancillería no presentó candidatura alguna para esa elección (Valencia, s/f).

Análogo a estos principios y declaratorias internacionales, en el contexto ecuatoriano, especialmente de los que el Ecuador es parte, la Carta Política de 2008 en el Capítulo Cuarto de los derechos de las comunidades, pueblos y nacionalidades, en el Art. 57.- "Se reconoce y garantizará a las comunas, comunidades, pueblos y nacionalidades indígenas, de conformidad con la Constitución y con los pactos, convenios, declaraciones y demás instrumentos internacionales de derechos humanos, los siguientes derechos colectivos:". Direccionado por los objetivos del presente trabajo, omito la enumeración de algunos literales del Art. 57, acogiendo solamente dos numerales que proclaman contra el racismo y discriminación: 2. "no ser objeto de racismo y de ninguna forma de discriminación fundada en su origen, identidad étnica y cultural", 3. "El reconocimiento, reparación y resarcimiento a las colectividades afectadas por racismo, xenofobia y otras formas conexas de intolerancia y discriminación". Además, el domingo 10 de agosto de 2014 entró en vigencia el Código Orgánico Integral Penal, que en el Art. 176,

Discriminación.- La persona que salvo los casos previstos como políticas de acción afirmativa propague, practique o incite a toda distinción, restricción, exclusión o preferencia en razón de nacionalidad, etnia, lugar de nacimiento, edad, sexo, identidad de género u orientación sexual, identidad cultural, estado civil, idioma, religión, ideología, condición socioeconómica,...con el objetivo de anular o menoscabar el reconocimiento, goce o ejercicio de derechos en condiciones de igualdad, será sancionado con pena privativa de libertad de uno a tres años. Si la infracción puntualizada en este artículo es ordenada por las y los servidores públicos, será sancionada con pena privativa de libertad de tres a cinco años.

De la misma manera en la Ley Orgánica de Educación Intercultural ${ }^{4}$-campo que me corresponde analizar- en el apartado de los principios, literal v: “... Garantiza la igualdad de oportunidades a comunidades, pueblos, ... y desarrolla una ética de inclusión con medida de acción afirmativa y una cultura escolar incluyente en la teoría y la práctica en base a la equidad, erradicando toda forma de discriminación". Estos articulados recogen algunas viejas aspiraciones de

4 Ver también en el Capítulo Segundo de las declaraciones del Estado respecto del derecho a la educación en su Art. 5, literal a, de la misma Ley. 
las organizaciones indígenas, que han puesto en evidencia en sus reivindicaciones desde los años noventa, fundamentalmente.

El objetivo no es enumerar los artículos, los numerales y los literales, sino evidenciar los instrumentos legales que se pueden esgrimir para neutralizar desde las víctimas las operaciones de los discursos y prácticas racistas y discriminantes en todos los niveles reticulares. De esta manera, los articulados no constituyen un fin en sí mismo sino un abordaje como condición de posibilidad de empoderamiento de los "sectores" afectados como una caja de herramienta. Pero hacer hincapié solamente en aspectos constitucionales y legales, puede limitar a declarar que, en virtud de las pertinentes disposiciones jurídicas, no existe discriminación racial, pues todos los ciudadanos son iguales ante la Ley. Visto así el marco jurídico interno, puede constituirse en una trampa para invisibilizar la discriminación racial frente a los organismos internacionales:

El embajador Alfredo Pinoargote, Representante del Ecuador ante la Oficina de la Naciones en Europa, tuvo a su cargo la presentación... En su exposición introductoria, el embajador ecuatoriano apuntó que no existía discriminación racial sistemática, pero que las desigualdades existentes obedecían a los problemas sociales, económicos y estructurales típicos de todos los países en desarrollo (Valencia, s/f: 12).

La legislación nacional e internacional ha provocado importantes discusiones en las ciencias jurídicas, generando bases para las nuevas formas de entender la situación de la población indígena, y para que la cuestión indígena no siga siendo tendenciosamente tratada como un problema meramente cultural y tiendan a ser reconocidas sus bases jurídico-políticas, económicas (Ayala, 1996); a pesar de este carácter ambiguo del marco legal, indudablemente presenta condiciones favorables para articular las denuncias contra la discriminación racial, sin descuidar las siguientes preguntas ¿Están empleando estos mecanismos legales nacionales e internacional para denunciar y visibilizar todo tipo de discriminación racial? Y si los hacen ¿Quiénes lo hacen? ¿Es posible denunciar a quienes ostentan el poder?

El 7 de enero de 2014 en el canal Ecuavisa, el presentador del programa contacto directo, Alfredo Pinoargote Cevallos, mencionó: "La libertad de expresión tiene su máxima expresión, valga la redundancia...pero hay un ambiente o un sistema de restricción a esa libertad, por ejemplo ya no se le puede decir a los gays maricas, a los afros no se les puede decir negros, a los ladrones no se les 
puede decir ladrones...”. Frente a este discurso discriminante, la asambleísta nacional Alexandra Ocles, presidenta del Grupo Parlamentario por los Derechos de los Pueblos y Nacionalidades, interpuso una denuncia ante la Superintendencia la Información y Comunicación (SUPERCOM), argumentando que "denigró al pueblo afroecuatoriano y a las personas con diversa orientación sexual" (El Telégrafo, 4 de abril de 2014). Lejos de entrar en discusión de la estadística de quienes denuncian o no, lo cierto es que el Estado ecuatoriano ha promovido dispositivos legales contra el racismo, una de las formas de reconocer su existencia, por ejemplo, es el Plan Plurinacional para Eliminar la Discriminación Racial y la Exclusión Étnico y Cultural, aprobado como política pública por el presidente Rafael Correa, mediante Decreto Ejecutivo No. 60 de 13 octubre de 2009, establece un programa ambicioso referido a la justicia y a la legislación contra el racismo. No obstante de esta virtud jurídica desde el Estado, también los movimientos sociales, indígenas, afros deben de declararse una campaña permanente a partir de espacios educativos de todos los niveles con el objetivo de declarar cero racismos. Siendo, el campo educativo el escenario adecuado para cuestionar a las ciencias y posciencia que justifican la existencia del razas humanas.

\section{Neorracismo}

La tecnología marca hoy los derroteros de la ciencia ${ }^{5}$. Marca asimismo un cambio de rumbo respecto de los cánones impuestos por la ciencia moderna, no solo porque la tecnología digital con su enorme potencialidad atraviesa absolutamente todas las disciplinas científicas sino también porque la informática surgió directamente como tecnología. Este acontecimiento representa una ruptura con lo que entendió la modernidad por ciencia e instaura una nueva forma de conocer el mundo y relacionarse con él. Esther Díaz, a esta nueva forma de saber la denomina "posciencia" (2002: 23)

Díaz (2002) sostiene que ni la partición del átomo ni la biotecnología podrían haber llegado a tener el desarrollo y la potencia que alcanzaron sin la informática. Desde esta perspectiva la fisión del átomo, la informática y la biotec-

5 La aparición de las primeras computadoras digitales electrónicas ocurrió en plena Segunda Guerra Mundial. El primer prototipo (el ENIAC) se utilizó fundamentalmente para el cálculo de proyectiles y para el proyecto que culminó con la fabricación de la bomba atómica. Ése fue el momento crucial en el que la tecnología dejó de ser secundaria en la ciencia y pasó a ocupar el lugar prioritario que hasta hoy conserva (Díaz, 2002: 23). 
nología se interrelacionan de modo interesante y se establecen alianzas. Estos tres campos -reacción en cadena atómica, ingeniería genética e informáticase caracterizan, entre otras cosas, por la capacidad de reproducirse al infinito.

Las sociedades se han dividido -en términos gramscianos- en intelectuales tradicionales e intelectuales orgánicos ${ }^{6}$. Carlos Marx destaca que la sociedad en la modernidad y la repartición desigual del capital se simplifica en la formación de dos grandes clases caracterizadas por la distribución: el proletariado y la burguesía. La burguesía dispone de los medios de producción; o sea, del denominado capitalismo, mientras el proletariado sólo puede dar su fuerza de trabajo. A lo largo de la historia se ha segregado a las personas por su casta, su clase, su religión, su color de piel, sus ideas o su sexualidad y siempre se han elaborado justificaciones para las injusticias que unos pocos han impuesto a la mayoría (Díaz, 2002). En esta línea de reflexión conexa cabe la argumentación de Aníbal Quijano: “el patrón de dominación entre los colonizadores y los otros, fue organizado y establecido sobre la base de la idea de "raza", con todas sus implicaciones sobre la perspectiva histórica de las relaciones entre los diversos tipos de la especie humana" (2001: 120).

Ahora, con la aparición de la ingeniería genética (posciencia), la sociedad contempla la posibilidad de una nueva y más grave forma de segregación: la que se basa en el genotipo. Es decir, en el conjunto de información genética que posee un individuo. A partir de esta información se discrimina, por ejemplo, a quienes tienen propensión a determinadas enfermedades excluyéndolos de ámbitos laborales y sociales en general.

Se debe recalcar que toda la humanidad cuenta con la misma esencia genética de 23 mil genes que les proporcionan características únicas como especie. En término reales, la diferencia entre individuos es mínima, menor al 1\%, pero es suficiente para proporcionar individualidad incomparable. Nadie mejor, nadie peor, solo diferente. Los individuos con genes comunes suelen compartir también otros elementos como área geográfica, folklore, conocimientos, ideologías y eso conforma lo que llamamos etnia; cientos repartidas en el mundo, todas con similar $\mathrm{ADN}^{7}$. César Paz y Miño, alerta que los datos genéticos ac-

$6 \quad$ El intelectual tradicional es el filósofo, el artista, el literato. Mientras los intelectuales orgánicos no se limitan a describir la vida social de acuerdo a reglas científicas, sino más bien expresan mediante el lenguaje de la cultura, las experiencias y el sentir que las masas que no pueden articular por sí mismas.

7 En 1953 James Watson y Francis Crick descubrieron la estructura y el comportamiento del ADN, lo que le valió el nobel de medicina en 1962. El ADN es el responsable del parecido entre padres e hijos, y que exista un molde común para cada especie. Contiene toda la información genética, las instrucciones de 
tuales han servido para revivir viejos conceptos raciales, porque existen investigadores que pretenden caracterizar y clasificar los antecedentes biológicos, culturales y aún de comportamientos, con la intención de discriminar. Entre los genetistas neorracistas existe el "mito del africano enfermo" (El Telégrafo, 18 de mayo de 2014). En este sentido el neorracismo se expresa de dos maneras; por un lado, en la reavivación de los viejos conceptos raciales y por otro lado en la emergencia de la ciencia genética. Ambas expresiones, constituyentes en uno de los poderes científicos, cuyas estrategias de poder forman retículas que se expanden y atraviesan en los eslabones más finos de las aulas universitarias y en todo el sistema escolar y como consecuencia transversa todos los cuerpos sociales. En este sentido, viene al caso las investigaciones sobre las relaciones específicas que se tejen entre saberes y poderes.

Ahora bien, tengo la impresión de que existe, e intenté demostrarlo, una perpetua articulación del poder con el saber y del saber con el poder. No basta con decir que el poder tiene necesidad de éste o aquel descubrimiento, de ésta o aquella forma de saber, sino que ejercer el poder crea objeto de saber, los hace surgir, acumula informaciones, las utiliza... El ejercicio del poder crea perpetuamente saber e, inversamente, el saber conlleva efectos de poder (Foucault, 2010: 608).

Las reivindicaciones de los viejos conceptos raciales y el desarrollo de la posciencia (ingeniería genética) no se ejerce por sí sola ni de forma aislada, no es posible el ejercicio del poder sin el ejercicio del saber, es imposible que el saber no engendre poder, menciona Michel Foucault (2010). Estos dispositivos neorracistas -posciencia-poder y sus tendencias deben ser visibilizadas y combatidas en todo el sistema educativo, haciéndoles circular los conceptos genéticos verdaderos que aproxima la humanidad, dar esperanza de una convivencia pacífica, plurinacional e intercultural, unidad en la diversidad. Estos valores y principios elementales de los derechos humanos sólo es posible trabajar desde

diseño de todos y cada uno de nosotros. Y del resto de seres vivos, desde la bacteria más simple hasta el organismo más complejo. En el ADN hay decenas de miles de genes. Son los encargados de fabricar las proteínas necesarias para el desarrollo de las distintas funciones vitales. La mayor parte del ADN está en el núcleo de las células. Cada célula de nuestro cuerpo almacena una copia de esta información. Cada molécula de ADN se compone de dos cadenas de nucleótidos que se cruzan entre sí en forma de doble hélice. Es esa imagen tan característica que nos viene a la mente cuando se habla del ADN. La función principal de las moléculas de ADN es el almacenamiento a largo plazo de la información genética. ADN es a menudo comparado con un conjunto de planos para los seres humanos. ADN es la molécula que contiene la información de la vida. (http://www.astromia.com/astronomia/adn.htm). 
las aulas escolares con el impulso de las prácticas interculturales como propone a través de los materiales didácticos desde los estudios interculturales de la Universidad Nacional de Chimborazo. No cuestionar el racismo, neorracismo o todo tipo de discriminación sería como legitimar y naturalizar su existencia. Sería como la mayoría de los darwinistas de los nuestros días reivindicaran que Darwin nunca fue racista, sabiendo que este científico en su obra "El Origen de las Especies" aventuró que era necesario que las razas inferiores desaparezcan y que para nada era conveniente que los pueblos desarrollados intentasen protegerlas para que sigan viviendo. Y en otra parte de esta misma obra consideró a los nativos de Australia y a los negros, prácticamente, en un pie de igualdad con los monos y sostuvo que debía desaparecer. En cuanto a esas otras razas que consideraba "inferiores", opinaba que era esencial impedir su multiplicación, de modo que termine extinguiéndose (Harun Yahya, 2003). Estos datos evidencia cómo las ciencias se van evolucionado, cambiándose para (re) configurar aprobando y justificando la existencia del racismo y la discriminación, "antes", la ciencia ${ }^{8}$ darwinista y hoy la ingeniería genética, sin que esto signifique una ruptura total entre estas ciencias, aunque resemanticen las categorías, por ejemplo, en la antigua Gracia, los filósofos Platón y Aristóteles ${ }^{9}$, admitieron la eutanasia, o sea la pena de muerte provocada voluntariamente en el caso de enfermos considerados irrecuperables. Además, la eugenesia como ciencia es la rama de la manipulación genética que estudia el mejoramiento de la especie humana. Busca mejorar las cualidades indeseables de la raza humana. Este propósito ha sido buscado desde hace mucho tiempo. La semántica de la eugenesia ha sufrido una serie de cambios; Esther Díaz (2002) menciona que tradicionalmente se llama "eugenesia" a la aplicación de las leyes biológicas de la herencia al perfeccionamiento de la especie humana. La eugenesia actual es producida desde la biotecnología, que mediante la manipulación de genes "diseña"

8 Las ciencias naturales se utilizaron para definir diferentes razas en términos biológicos y genéticos. Luego del nazismo los conceptos científicos de raza perdieron fuerza y validez (De la Torre, 2002: 20).

9 Según Platón (hacia 427-347), la sociedad modelo ha de estar compuesta de hombres sanos: "Quien no es capaz de vivir desempeñando las funciones que les son propias no debe recibir cuidados, por ser una persona inútil tanto para sí mismo como para la sociedad" (República, 407). Aristóteles (384-322) escribe a propósito del infanticidio: "En cuanto a la exposición o crianza de los hijos, debe ordenarse que no se críe a ninguno defectuoso, pero que no se exponga a ninguno por causa de los muchos hijos, en el caso de que la norma de las costumbres prohíba rebasar cierto límite; la procreación en efecto debe limitarse, pero si algunos tienen hijos por continuar las relaciones más allá del tiempo establecido, deberá practicarse el aborto antes de que se produzca en el embrión la sensación y la vida, pues la licitud o ilicitud de aquel se definirá por la sensación y la vida" (Política, 1335). 
seres superiores. Esta idea de superioridad e inferioridad de seres argumentada desde la ciencia, también es corroborada y robustecida con los discursos y prácticas cotidianas e institucionales racistas y discriminantes que funcionan en forma microscópica y capilar, incluso. En tanto configuración ideológica desarrollada a partir de la confluencia de nuevos saberes y disciplinas fecundadas desde la época de las Ilustración europea del siglo VXIII, el racismo va organizando, prejuicios morales y estereotipos estéticos que apoyados en certezas científicas y seudocientíficas tienden a sentar las bases de un consenso hegemónico sobre la cuestión del llamado problema de los “indios” (Gómez, 2006) configuración estrecha entre el racismo-ciencia, poder-saber.

\section{Discursos de discriminación racial en la educación}

El primero de octubre de 2014 -el día de la presentación de la propuesta pedagógica de cómo implementar la interculturalidad en los centros educativos urbanos que contribuyeron en la investigación "La interculturalidad en el modelo educativo de la educación general básica en el cantón Riobamba"- uno de los profesores asistentes luego de la socialización menciona:

...cuando nosotros preguntamos de dónde somos, respondemos de Quito, de Riobamba; renegamos nuestras raíces, porque estamos siendo alienados...no podemos obligar a los estudiantes indígenas que sigan siendo indígenas, porque algunos, hasta los apellidos quieren cambiar. Yo conocí estudiantes con un apellido, ahora ya se han cambiado. Hasta de nombres se cambian. No les gusta el nombre Segundo Toribio, hoy se llaman Daniel Santiago...Conozco también que en el gobierno de Rodrigo Borja se creó la Dirección de Educación Intercultural Bilingüe, ahí, los compañeros saben que se trabajó con el MOSEIB ¿Dónde están los resultados de ese trabajo intercultural?... Hoy no hay como reconocer a los indígenas, sino solamente en sus peinados...

Otro docente:

...Yo sugiero que esto del indigenismo, esto de la humillación al indígena, lo veamos desde el aspecto de la modernidad, porque años atrás en mi tesis de pregrado hice algo parecido, sobre la humillación al indígena, la humillación del indígena en la urbe, como el estudiante viene y no es aceptado, cometí un error en creer que existe una humillación al indígena, cometí el error en creer que el mestizo trataba de influenciar al indígena. Aquí escuché algo similar, no creo 
que haya pérdida de cultura ni creo que haya humillación al indígena, simplemente hay modificación de la cultura...

Aquí surgen varias preguntas y parafraseando a Dipesh (1999) podemos decir ¿Quién habla en nombre del subalterno? Dicho de otra manera ¿Quién hala en nombre del humillado? ¿Es la misma versión de quien ha sufrido las humillaciones, discriminaciones raciales, injusticias históricas que las de quien no ha sido afectado? Los testimonios ¿No es otra forma de expresar la discriminación racial? Se destaca que los discursos de docentes universitarios en un escenario académico, son discursos estructurados, "cuidadosos", lleno de cuestionamientos a los indígenas y evidente búsqueda de rasgos distintivos ${ }^{10}$ en la dialéctica del yo y del otro, la dialéctica hegeliana del conocimiento donde hay un yo, hay otro. Aquí encaja lo que Blanca Muratorio (1994) señala: "El Otro es aquí el Indio imaginado, no el Indio como el sujeto histórico". Si analizamos los testimonios a luz de las reflexiones de Teun A. Van Dijk, (2006) el racismo opera "tras bambalina"; es decir, se puede decir el racismo que practican las elites en la actualidad es un racismo oculto, se disfraza en otra clase de prejuicios y se naturaliza. Este tipo de discurso de discriminación racial puede ser más peligroso que el mismo discurso directo y brutal, en el sentido de ejercer ocultándose en la estructura difusa que no permite ninguna reacción. Parafraseando a Pierre Bourdieu (2007 [1994]) se puede que las formas suaves y larvadas de violencia discursiva discriminante tienen tantas más posibilidades de imponerse como única forma de ejercer la dominación, y por su carácter "tras bambalina" parece difícil de resistir. A esta forma discursiva podemos llamar "racismo simbólico".

Los testimonios parecen no ser solamente una expresión personal, "sino una combinación personal de éstas y otras ideologías, actitudes, creencias, valores, modelos y otras representaciones sociales y personales" (Van Dijk, 2006: 346), pero también se puede percibir un afán de ocultar, tergiversar la existencia del racismo, aunque este discurso no es generalizado en todos los docentes.

10 "Para el médico e investigador Harold P. Freeman, calificar a un grupo étnico, a partir de su color de piel, es algo que se aleja de la realidad científica" (Diario El Comercio, 28 de noviembre de 2010). Científicamente, ni el color de la piel ni los ojos determinan el origen étnico ¿No sería burdo identificar a un indígena por su peinando? Al decir, Víctor Espín, Director de Área de Genética del IESS: “...Cuando se descubre el ADN y se realizan estudios de genoma de la especie humana, constatamos que el genoma de la especie humana es el mismo en todos los seres que habitan en este planeta" (Diario El Comercio, 28 de noviembre de 2010). 
En un bus público al ver un grupo de indígenas en el Parque Infantil, una estudiante le pregunta a su compañera "¿Qué hacen, qué hay?” Y le responde: "Están en el levantamiento, qué más pueden hacer". En un riña entre borrachos en un barrio periférico emplean palabras soeces: "Indio hijo de p...; yo no soy longo como tú; indio, indio,..." repetían, pero mientras más repetía la palabra "indio" con su adjetivo denigrante más deslegitimaba a su oponente. Una reportera de un canal local le pregunta "¿Qué hacer para tener limpia la ciudad?" Y le responde "privar el ingreso de los indios a la ciudad, ellos son muy sucios, dejan la basura por todo lado, son muy sucios". En una discusión en un barrio periférico de la ciudad de Riobamba, una vecina le dice: "vecina ponga la basura en su lugar, usted quiere vivir como en el campo, esto no es campo". La otra vecina le responde "Es la primera vez que pongo aquí, este barrio está lleno de indígenas, son ellos los que ensucian el barrio, ellos quieren vivir como en el campo,...". Una maestra mestiza en la parroquia Santiago de Quito le dice a un supervisor indígena: "ya viene el rocoto, verdugo solo a joder viene,... indio verdugo". Efectivamente, estos testimonios reflejan los imaginarios llenos de estereotipos raciales en el espacio educativo y en otros niveles institucionales y cotidianos. En este sentido la educación, por un lado cumple la función de movilidad social, por otro lado, (re) produce las jerarquías y discriminaciones raciales en los patios, en las aulas, en los pasillos de la educación de Riobamba, aunque estas lacras sociales parece en todo el país. Este paso, por las escuelas, los colegios, los institutos, las universidades para Carlos de la Torre (2002), por lo general, son experiencias traumáticas llena de vejámenes y obstáculos, generando incluso dificultades de aprendizaje y deserción escolar. Por eso, pronto esa voluntad y fuerza de estar en la ciudad, de estudiar en las escuelas urbanas, se ve bloqueada, sobre todo para quienes tienen interferencias lingüísticas, vestimentas indígenas.

De acuerdo al trabajo de campo etnográfico, la categoría más recurrente es el "indio", una categoría históricamente devaluada, (neo) colonizada, una de las formas de representar simbólicamente el poder absoluto de los mestizos. De acuerdo a nuestra etnografía y las narrativas de nuestros entrevistados no existen suplicios y castigos físicos como revela en la investigación que hizo Carlos de la Torre (1996) en su libro El racismo en el Ecuador. Sin embargo no se puede negar de los rituales racistas acompañados de mofas, humor, parodias reiteradas y asociadas a risas de los compañeros, al mal uso de las consonantes "gramatización" en vez de "dramatización" como relató en una de las entrevistas. El testimonio revela el ritual de exclusión desde los más finos y átomos de 
discursos y desde los rechazos e indiferencias. Circula lo que Foucault sugiere que el racismo no es simplemente la asignación de valores jerárquicos a una gama de expresiones fenotípicas tales como el cabello, formas de peinado, el color de la piel y la forma de la nariz. Como explica Ann Stoler, Foucault ve el racismo, más bien como una red de inteligibilidad. Como una gramática que no se refiere a un determinado grupo de personas sino a una división más generalizada dentro del cuerpo político (Nelson, 2006). En esta línea cabe la propuesta de Foucault (2011) de desenmascarar los rituales, parodias, mofas y hacerlos aparecer como lo que son: realidades meramente arbitrarias ligadas al modo de vida colonizante. "Hay que poner en "en juego", exhibir, transformar, y dar la vuelta a los sistemas que apaciblemente nos ordenan” (2011: 377).

\section{Vestimenta indígena signo de discriminación racial}

En la materia de ICA nos dio las reglas de cómo vestir. Nos dijo cómo debemos vestir para las exposiciones. Nos dijo que los estudiantes siempre venimos informales y los profesores formales. Es hora de cambiar los roles. Los hombres deben venir con corbatas, pantalón de tela, leva. Pero se abstuvo en comentar y sugerir vestimenta formal a las mujeres. Yo en ese momento me sentí mal y me pregunté ¿Qué significa vestir bien? Bueno, en mi casa tuve problemas porque quería comprar una chaqueta y mis padres no quisieron saber nada... (Estudiante, 5 de octubre de 2014).

No queremos utilizar el anaco porque sentimos miedo a que nos rechacen al grupo al que pertenecemos. Porque ya han rechazado a mis compañeras. Tengo miedo de ser vista como bicho raro. Pero también no me pongo el anaco porque se me pega mucho y no me permite mover con facilidad (Estudiante, 4 de junio de 2014).

Cuando yo estuve en el cuarto curso, vino al colegio una chica indígena de Colta a tercer curso. Ella llegó puesta una bayeta roja sobre el suéter del colegio, collar lleno de su cuello, todos quedaron mirando con sorpresa. Cuando se presentó habló con muchas interferencias lingüísticas, cambió la vocal "i" por la "e" y la "o" por la "u", Entonces ya empezaron a ver más aún como rara, inferior y con burla escondida. Ella ya empezó a sentirse excluida y de hecho la excluyeron. Me dolió mucho porque yo también pongo el anaco, pero no pude hacer nada para intervenir, a mí nunca me faltaron el respeto porque yo hablo bien el castellano. Creo que por eso fui la primera vicepresidenta indígena del gobierno estudiantil del año lectivo 2013-2014. Continuando con la historia, su pronun- 
ciación en el castellano le había hecho sentir súper mal, hasta había llorado. Prefirió no hablar mucho, creo que tenía miedo a equivocarse. La burla era disimulada pero la indiferencia le excluyó automáticamente. En el recreo pasaba sola. Cuando remedaron la pronunciación yo le miraba fijamente y bajaron la mirada. A ningún profesor le interesó ese caso, nadie habló sobre ese tema.; para bien o para mal. En quinto y sexto curso ya dejó su vestimenta que trajo de Colta. Ya no vi con sus collares rojos ni bayeta. Su forma de vestir cambió casi en su totalidad, pero eso ayudó para estar en el grupo (Estudiante ${ }^{11}, 15$ de mayo del 2014). Me comentó una compañera lo que habían pensado sobre mí: cuando yo entré a octavo año, era tímida y no hablaba, me daba miedo. No tenía miedo porque era indígena sino porque estuve pasando de una etapa a otra. Me habían visto puesto anaco y entre ellas habían comentado: "Ve esta indígena ya ha de perder el año, de seguro se quedará para el supletorio de primera y en todas la materias". En el transcurso del tiempo empecé a sacar solo diez. Ya, en el medio ciclo la licenciada de orientación vocacional vino al curso y nos dijo que había tres lugares para los mejores promedios del curso. Me ubicaron en tercer lugar. Fue toda una sorpresa para mis compañeras. Se quedaron sorprendidas y admiradas, creo que mi nota tapó la boca sobre lo que habían dicho sobre mi anaco. Los profesores me apreciaron mucho" (Estudiante, 3 abril de 2014).

Entramos a un lugar llamado "fantasías del oro" a comprar unas vinchas, mi mamá puesto anaco, bayeta, sombrero y yo con el calentador. Los indígenas aumentamos la "s" a ciertas palabras. No quiero hablar porque me da ganas de 1lorar,... Bueno, mi mamá hizo un pedido, diciendo: traerás. El señor le respondió con un tono bien enojado: "No se dice traerás sino traerá, aprende a respetar”. Mi mamá quedó apagada, pero yo le dije que mi mamá no estaba faltando el respeto. Él me dijo si estaba faltando el respeto, entonces le pedí disculpas, pero también le dije que tiene que atender de buena manera porque así se iría a la quiebra... (Estudiante, 29 de septiembre de 2013).

La sociedad chimboracense, presume ser una sociedad no racista, sin embargo la investigación realizada en algunos centros educativos y los testimonios citados pone en evidencia de su existencia. Uno de los puntos que aquí interesa analizar es como los imagineros mestizos dominantes pone en juego un conjunto de mecanismo e instituciones para mantener una situación de dominación. Las instituciones educativas parecen ser más efectivas en la pérdida de la indumentaria, lengua y cultura. La vestimenta indígena sufre discriminaciones y estereotipos constantes en el campo educativo, se visibiliza la imposición de

11 No constan los nombres y apellidos por solicitud de los entrevistados y entrevistadas. 
vestimenta mestiza sobre lo indígena. Dicho de otra manera, la relación entre la vestimenta indígena y mestiza, también es una "relación de poder, en la que el segundo subordina al primero, el cual emite - parafraseando a Edward Said (2009) - la noción colectiva que define el "nosotros" contra todos aquellos no blanco-mestizas".

Para algunos mestizos, el vestir con la indumentaria indígena significa "un vestir mal", sinónimo de "presentarse mal", en este sentido, se evidencia la doble vía de discriminación: la indumentaria y la persona. Las personas con vestimenta indígena mencionan haber sufrido algún tipo de racismo: actitudes y gestos negativas, hostilidades, violencia en forma implícita o explícita. La vestimenta o todo lo relacionado con lo indígena es irracional, depravado (perdido), infantil, atrasado; mientras que los del blanco-mestiza es racional, virtuoso, maduro, desarrollado (Said, 2009) por eso es legítimo que el segundo actúe como agente civilizador en la región de Chimborazo y cualquier sugerencia y acción de dominio, sin importar los medios para la consecución de un fin, es por su bien y justificarse como poder moral, es como decir "tengo razón en castigar, puesto que tú sabes que está mal robar, matar,..." (Foucault, 2008: 28 y Foucault, 2011).

El discurso sobre la "formalidad" y la "informalidad" en el modo de vestir conlleva cargas discriminantes y excluyentes. De acuerdo al trabajo de campo las vestimentas indígenas, en ocasiones ni siquiera aparecen como un traje "informal". "No pueden venir con esa ropa" “por qué pones el anaco y no el uniforme de la escuela?" circulan en el ambiente escolar. Frente a estos dispositivos discriminantes los padres y madres de familia indígenas luchan permanentemente para que sus hijos no sean absorbidos. En términos de Gladys Villavicencio, al despertar la conciencia social indígena, hecho que se da en mayor número de indígenas, se están dando dos alternativas distintas al sometimiento: o por evadirse destruyendo los signos externos de la segregación (vestimenta, cabello largo en el indígena hombre, idioma, etc.), o enfrentarse al grupo mestizo asumiendo actitudes de rebeldía y de rechazo (2006:158). La primera reacción se observa en la mayor parte de los niños y jóvenes indígenas de Chimborazo. Los hallazgos en la investigación revelan que para la mayoría de los escolares, colegiales y universitarios indígenas es más fácil absorberse, acomodarse en el mundo mestizo sin su vestimenta, sin su lengua.

La investigación revela que la vestimenta indígena es empleada como un disfrace de los desfiles, de las danzas, de los bailes, de las exhibiciones, presentaciones de "doñas". Claramente se evidencia que la ropa indígena ni siquiera 
es una manera de "vestir informal" sino un disfrace y aquí cabe lo que cita Gonzalo Rubio Orbe: "Un matrimonio aborigen me decía: "Estos longos se visten como si fueran a bailar San Juan". Disfrazados para bailes" (1987). Por otro lado, el traje indígena es asociado a lo sucio, de mala presentación; argumentación justificada para "sobredimensionar" o valorar a un pueblo o nacionalidad indígena en detrimento de otra. Los discursos de admiración y respeto al pueblo indígena otavaleño, destroza y estereotipa al pueblo indígena de Chimborazo, asociando con "malos hábitos", "descuidados en la higiene". Algunos entrevistados mestizos hacen un juego de (re)presentaciones, constituyéndose en los imagineros. El discurso de algunos entrevistados sobre los otavaleños como personas "envidiables" por su "pureza" y "limpieza" construye sujetos o hace que sean sujetos. Contrariamente, crean imaginarios indígenas de Chimborazo con particularidades sesgadas, menospreciadas; de cierta manera, legitiman su dominación, (re) definen nuevas identidades despojando y reprimiendo las identidades kichwas. Aníbal Quijano (2001) sostiene que así se impuso el patrón de poder, cuyos ejes específicos son: a) la existencia y la reproducción continua de esas nuevas identidades históricas; b) la relación jerarquizada y de desigualdad entre tales identidades mestizas y no mestizas y de dominación de aquellas sobre éstas, en cada instancia del poder, económica social, inter-subjetiva, política.

Ciertamente las representaciones que hace el mundo mestizo de los indígenas, es siempre una manera de controlar, haciéndole devaluar su vestimenta, su lengua, etc. Aunque también este "monopolio de ese poder de representación está siendo cuestionado -en un campo de lucha multidimensional- por los mismos representados quienes, cansados de jugar un rol secundario en una imagen del pasado creado por otros, retoman el escenario político para convertirse en sus propios imagineros" (Muratorio, 1992: 9), o en término históricos los indios muestran signos de reapropiación de la capacidad para representarse a sí mismos (Dipesh, 1999). De acuerdo a estas argumentaciones y los resultados del trabajo de campo, no hay un "consenso ideológico", de admitir la pasividad de los estudiantes indígenas en los grandes centros educativos de la ciudad de Riobamba, sería negar la capacidad de agencia de la juventud, tema que es tratado en el siguiente apartado. 


\section{Resistencia al monopolio de representación en la educación}

James Scott (2000) en su obra Los dominados y el arte de la resistencia desafía a aquellos teóricos que entiende la hegemonía ${ }^{12}$ como "consenso ideológico"; Scott enfatiza la falta de consenso en las situaciones sociales y educativas de dominación. Los dominados saben que son dominados, saben por quiénes y cómo son dominados; lejos de aceptar o consentir a esa dominación, inician toda clase de formas sutiles de vivir, hablar de, resistir, socavar y confrontar los mundos desiguales y de concentración del poder en los que viven (Roseberry, 2007). Aquí cabe incorporar el testimonio de una alumna:

Una maestra y coordinadora del Campo de Acción me dijo: Todos debemos venir con una ropa formal para la clausura, yo le dije que utilizo el anaco y no puedo venir con los tacos sino con las alpargatas. Ella me insistió que debo venir obligatoriamente con los tacos. Yo le dije que no me puede obligar, hasta la rectora me dijo que es opcional. Mis compañeros me apoyaron aduciendo que yo siempre me visto así. La profe se optó en no decirme nada más (Entrevista, Ruth Micaela, 2 de abril de 2014).

Este discurso refleja la infraeducativa ${ }^{13}$ de los estudiantes indígenas. Con este término se pretende definir, una gran variedad de formas de resistencia discretas y no discretas que recurren a formas indirectas y directas de expresión. En este sentido la población estudiantil indígena asume claramente la posición más activa y dispuesta a la confrontación, y esta acción y la confrontación se da, dentro de las mismas instituciones educativas.

Los padres y madres de familia entran en este juego de lucha, negociación con los profesores por sus representados, se resisten en sustituir el anaco por la falda, aunque no todos entran en esta resistencia y en caso de los varones estudiantes no usan definitivamente la vestimenta al menos dentro de las jornadas pedagógicas. En este sentido, la mujeres indígenas son quienes sufren la doble discriminación; tanto por su origen étnico como por su condición de mujer.

12 William Roseberry propone utilizar el concepto de hegemonía no para entender como consenso sino para entender como lucha; las maneras en que las palabras, imágenes, símbolos, formas, organizaciones, instituciones y movimientos utilizados por las poblaciones subordinadas para hablar, entender, confrontar, adaptarse o resistir su dominación son moldeadas por el mismo proceso de dominación (2007: 127).

13 James Scott (2007) emplea la categoría infrapolitica para designar una gran variedad de formas de resistencia muy discretas que recurren a formas indirectas de expresión. 
Se observa que los niños y jóvenes indígenas en las escuelas urbanas no emplean su vestimenta, sin embargo, los días festivos, programas institucionales son bien aprovechas para emplear sus vestimentas, más allá de si hay folklorización o no desde la estructura. Estos hechos hace notar que aquí encaja la frase célebre de Michel Foucault ${ }^{14}$ : "donde hay poder hay resistencia". La lucha desde los indígenas es continua contra la baja autoestima, autoimagen nacional negativa, la vestimenta indígena devaluada, desarraigo, desinterés por los aspectos culturales e históricos, tenencia patológica a copiar modelos extranjeros, endorracismo, y vergüenza étnica, indiferencia en la relación alumno y docente (Quintero, 2003)

De acuerdo al trabajo de campo, algunos padres de familias indígenas mencionan que han tenido que negociar, dialogar con ciertos docentes y autoridades educativas para que sus hijas no dejen por lo menos el anaco, aunque esta tendencia no es generalizada; en el sentido de que no todos los representantes pretenden mantener su indumentaria en las aulas escolares ni todos los docentes rechazan la vestimenta indígena. En este juego de "estiras y aflojas" parece no cumplir ningún rol los instrumentos legales internacionales ni nacionales, ya por el desconocimiento ${ }^{15}$ o por la "incapacidad" de denunciar, o por la indiferencia de ciertas autoridades educativas. No obstante, en esta lucha, todo tipo de alianzas discursivas cabe, por ejemplo, la asunción del presidente del Ecuador, Rafael Correa, a favor de la campaña mundial contra el racismo ${ }^{16}$ mostrando un racimo de bananas en sus manos en una fotografía de su cuenta de Twitter, no solo es bien vista, sino que ven la necesidad del descenso y circulación en todos los niveles sociales, políticas, educativas, etc., como parte de la acción positiva contra el racismo. En esta línea, continúa siendo necesidad latente "de dar amplia difusión a la información acerca de los recursos internos disponibles contra los actos de discriminación racial" (Valencia, s/f: 16).

Los entrevistados y entrevistadas están convencidas que el racismo es una ideología de poder sustentada en la falsa creencia de la existencia de razas hu-

14 Michel Foucault es un brillante analista de poder, creo que lo que le costó explicar es cómo se resiste el poder.

15 De acuerdo a las entrevistas en las comunidades indígenas argumentaron no conocer los instrumentos legales ni internacionales, ni ecuatorianas que condenen la discriminación racial, aunque algunos dirigentes saben que tienen derecho y es inadmisible en esta época, el racismo. Esta "duda" no ocurre en los dirigentes de las organizaciones indígenas que han sido influidos por los medios de comunicación y socializados en los cursos de capacitaciones.

16 El lanzamiento despectivo de una banana contra un jugador negro en España, provocó que el presidente escribiera desde Ecuador, el mayor productor y las mejores bananas del mundo, rechazamos el racismo, somos todos macacos. El secretario de comunicación, Fernando Alvarado, también apareció con una banana rechazando el racismo en todas sus facetas. 
manas. Aseguran que los indígenas han sido históricamente privados de servicios básicos y comodidades debido al racismo con la idea de superioridad e inferioridad. Paralelamente plantean mayor acceso a la educación, a los espacios políticos y económicos de toma de decisión de grupos históricamente discriminados, a la par debe alentarse y operarse el nivel concientización y compromiso desde las autoridades educacionales en relación a la lucha contra la discriminación, esta acción debe conllevar el porcentaje real de recursos fiscales que se invierten para combatir la pobreza y la exclusión generada por factores de racismo, de lo contrario podría ser considerado como la ausencia de una política del Estado que permita garantizar los derechos humanos a los sectores más vulnerados por factores de racismo (Plan Plurinacional, 2012). Y, Quienes colaboraron en las entrevistas, ven a la educación como una herramienta que les permitirá el ascenso social y el conocimiento de los códigos de la cultura dominante. La educación es uno de los campos que mejor aporta no solamente para la resistencia sino a la movilidad social. Carlos de la Torre (2002) señala que ahora se busca el conocimiento de los códigos de la sociedad blanco-mestiza no solo para integrarse y poder sobresalir en ella, sino también cómo una manera de resistir a la dominación étnica-racial.

\section{Conclusiones}

En Riobamba y en el país, el racismo es un asunto de todos los días, más sin embargo pocos son los que conocen sus fuentes y las maneras en que se han instalado en la mentalidad colectiva a lo largo de la historia riobambeña -espacio de colonialismo interno según Hugo Burgos (1970)- hasta convertirse en un sentimiento hegemónico (Gómez, 2006). Los espacios educacionales se constituyen parte de la circulación y reproducción de la discriminación racial, por un lado. Por otro lado, a pesar de ser un proceso traumático para los indígenas, contribuye indudablemente a la movilidad social.

Los testimonios, los resultados del trabajo etnográfico reflejan los prejuicios y discriminación racial a partir de la convicción de los blanco-mestizos normalizando y naturalizando su superioridad e ilustra su menosprecio repulsivo, tácito o explícito ante la población indígena de región Riobamba (Castellanos, 2006); esta apreciación ha sido y es transmitida de forma efectiva de generación en generación por medio de los mecanismos de educación y socialización. Por su parte el indígena se ha convencido de su inferioridad evadien- 
do los signos externos de la segregación como la vestimenta, lengua, cultura, aunque este hecho no es generalizado; por cuanto, se resisten desde una actitud insurgente, de negociación y de revitalización.

Las imágenes estereotipadas con las que se identifica la negatividad de indio quedan resaltadas tanto en los discursos cotidianos como en las prácticas institucionales y personales, "actitud que parte del supuesto en la inferioridad del indígena y que acaba creando en él complejos de dependencia y de infantilismo" (Villavicencio, 2006: 174). Problema que no está solamente en liberarse de los dominantes sino de uno mismo.

Los niños y jóvenes indígenas son víctimas de un trato discriminatorio que suele rayar en hostilidad por parte de sus compañeros de aula y de algunos maestros, que no observan igual comportamiento con sus alumnos de procedencia mestiza (Villavicencio, 2006) no obstante del contexto jurídico internacional y nacional y a pesar de los esfuerzos del Gobierno nacional para paliar la discriminación racial reflejado en la promulgación del Código Penal, el Plan Plurinacional para Eliminar la Discriminación Racial y Exclusión Étnica y Cultural, entre otras acciones. En este sentido las escuelas, tal como de hecho funciona sin planes y programas concretos para la eliminación racial, parece no ser una respuesta adecuada a la realidad plurinacional e intercultural. Hay, naturalmente, excepciones de maestros y estudiantes, pero las excepciones parecen ser neutralizadas en el proceso por la familia y el ambiente social (Villavicencio, 2006).

Los discursos y prácticas discriminantes circulan, también, en los eslabones más finos de la red de poder del sistema escolar. Éste cuenta con centros y puntos de apoyo invisibles, pocos conocidos; su verdadera resistencia, su verdadera solidez se encuentran quizás allí donde no se piensa (Foucault, 2011) como por ejemplo en discursos discriminantes "adornados", ocultos, románticos, constituyéndose en violencia discursiva simbólica. Si no es capaz de reconocer estos puntos de apoyo del poder en el sistema escolar se corre el riesgo de permitirles que continúen existiendo y de ver cómo se reconstituye esos discursos y prácticas discriminantes (Foucault, 2011). Reconociendo como punto de partida la capacidad de movilización y acción política de los movimientos sociales e indígenas, o todas entidades que quieran sumarse a esta causa de erradicación de la discriminación racial, se debe implementar una campaña nacional, más agresiva, en todos los niveles, contra la opresión y discriminación para una convivencia armónica intercultural y plurinacional. Esta parte a modo de sugerencia, más que conclusión. 


\section{Bibliografia}

Ayala Mora, Enrique

1996 Nueva Historia del Ecuador. Volumen 13 Quito: Corporación Editora Nacional.

Bourdieu, Pierre

2007 [1994] Razones prácticas sobre la teoría de la acción. Barcelona: Anagrama.

Foucault, Michel

2008 Un diálogo sobre el poder y otras conversaciones. Madrid: Alianza Editorial.

2010 Las redes del poder. Buenos Aires: Prometeo Libros.

2011 Obras esenciales. Buenos Aires: Paidós.

De la Torre, Carlos

2002 El racismo en el Ecuador. Quito: Abya-Yala.

Diario El Comercio

201028 de noviembre. Quito.

Diario El Telégrafo

20144 de abril. Quito.

201418 de mayo. Quito.

Díaz, Esther

2002 El conocimiento científico. En: Esther Díaz, La posciencia. El conocimiento cientifico en las postrimerías de la modernidad (pp. 14-38). Buenos Aires: Biblos.

Dipesh, Chakrabarty

1999 La poscolonialidad y el artilugio de la Historia: ¿Quién habla en nombre de los pasados “indios"? En: Saurabh Dube, Pasados poscoloniales (pp. 623658). México D.F.: Colegio de México.

García, Fernando

2007 Los pueblos indígenas del Ecuador: derechos y bienestar. Informe alternativo sobre el cumplimiento del Convenio 169 de la OIT. Quito: FLACSO.

Gómez, José

2006 Los caminos del racismo en México. México: Universidad Autónoma de Puebla.

Nelson, Diana

2006 Un dedo en la llaga. Cuerpos políticos y políticas del cuerpo en Guatemala del Quinto Centenario. Guatemala: Cholsamaj.

Orbe, Gonzalo

1987 Los indios: evolución histórica y políticas indigenistas. Quito: Corporación Editora Nacional. 
Plan Plurinacional para Eliminar la Discriminación Racial

Primera edición: septiembre/ 2009 y segunda edición: marzo/2010. SPO/ EC/2009/SS/RP/PI/3. Quito: Programa Desarrollo y Diversidad Cultural.

Quintero, María

2003 Racismo, etnorracismo occidental y educación. El caso Venezuela. Revista Acción Pedagógica, 12(1), 1-12.

Quijano, Aníbal

2001 Colonialidad de poder, cultura y conocimiento en América Latina. En: Walter Mignolo, El eurocentrismo y la filosofía de la liberación en el debate intelectual contemporáneo (pp. 117-134). Buenos Aires: Ediciones del Signo.

Roseberry, William

2007 Hegemonía y el lenguaje de la controversia. En: María Lagos, Antropología del Estado. Cuaderno de Futuro, 23, 117-13. La Paz: INDH/PNUD.

Said, Edward

2009 [1997] Orientalismo. México D.F.: Random House Mondadori.

Van Dijk, Teun

2006 Ideología. Una aproximación multidisciplinaria. Barcelona: Editorial Gedisa S.A.

Valencia, Luis

s/f El Ecuador y la discriminación racial. Disponible en: http://www.afese.com/ $\mathrm{img} /$ revistas/revista46/discriminacion.pdf

Villavicencio, Gladys

2006 Relaciones interétnicas en Otavalo. En: Pensamiento antropológico ecuatoriano (pp.157-180), segunda parte. Quito: Corporación Editora Nacional y Banco Central del Ecuador.

Yahya, Harun

2003 Los desastres producidos por el darwinismo a la humanidad. Turquía: Okmeydani.

Páginas web

http://easylearngenetics.net/what-is-genetics/what-is-dna/que-es-el-adn/ http://www.astromia.com/astronomia/adn.htm

Fecha de recepción: 9/3/2015; fecha de aprobación: 16/6/2015 